\title{
O SENTIDO DO TRABALHO DOS GARIS COLETORES DE RESÍDUOS DOMICILIARES
}

\author{
THE SENSE OF WORK OF GARIS COLLECTORS OF HOUSEHOLD WASTE
}

\author{
TISSIANY MELO MATO ${ }^{1}$ \\ TEREZA CRISTINA BATISTA DE LIMA \\ LUIS EDUARDO BRANDÃO PAIVA ${ }^{3}$ \\ SERAFIM FIRMO DE SOUZA FERRAZ ${ }^{4}$
}

\begin{abstract}
RESUMO: Este estudo teve como objetivo investigar os sentidos do trabalho no campo profissional dos garis coletores de resíduos domiciliar. A escolha desse tema se deu devido a importância deste serviço e de seus profissionais no contexto da sociedade, e o interesse em conhecer a percepção dos mesmos quanto ao sentido de trabalho que executam, nos âmbitos individual, organizacional e social. O referencial teórico abordou os temas trabalho, sentidos e significados do trabalho e o modelo das dimensões do sentido do trabalho, que foi utilizado para a elaboração do instrumento de pesquisa, com o propósito de atender aos objetivos específicos analisando as dimensões individual, organizacional e social do trabalho na perspectiva do trabalhador gari coletor. Tratou-se, então, de uma pesquisa qualitativa, descritiva, com uma amostra de 15 trabalhadores do serviço de coleta de resíduo domiciliar da cidade de Fortaleza, escolhidos aleatoriamente. Os resultados apontam que o trabalho possui sentido positivo para esses trabalhadores nas três dimensões de análise, permitindo o crescimento profissional, a valorização, o reconhecimento e a auto realização do indivíduo. Em contrapartida, constataram-se relações negativas nas unidades de contexto, reconhecimento contributivo perante a sociedade e autonomia do trabalhador. De modo geral, os resultados contribuem para se ter uma maior compreensão sobre os sentidos do trabalho dos garis coletores de resíduos domiciliares.
\end{abstract}

Palavras-chave: Sentido do Trabalho. Dimensões do Sentido do Trabalho. Garis Coletores.

ABSTRACT: The objective of this study was to investigate the meanings of work in the professional field of garbage collectors. The choice of this topic was due to the importance of this service and the waste collector to society, as well as the perception of this about the sense of work that performs in the individual, organizational and social spheres. The theoretical framework addressed the work, meanings and meanings of work and the model of the dimensions of the meaning of work, which was used for the elaboration of the research instrument, with the purpose of meeting the specific objectives analyzing the individual, organizational and social dimensions of the work. work in the perspective of the

Data de submissão: 25/12/2017 Data de aceite: 17/06/2018 Data de publicação: 08/08/2018 1 Graduada em Administração de Empresas pela Universidade Federal do Ceará (UFC).

2Professora do Programa de Pós-graduação em administração e Controladoria da Universidade Federal do Ceará (UFC). Doutora em Educação pela UFC.

3Doutorando em Administração e Controladoria pelo Programa de Pós-graduação em Administração e Controladoria da Universidade Federal do Ceará (UFC). Graduado e Mestre em Adminsitração pela UFC.

4Professor do Programa de Pós-graduação em administração e Controladoria da Universidade Federal do Ceará. Doutor em Administração de Empresas pela EAESP-FGV (Fundação Getúlio Vargas de São Paulo). 
worker gari collector. This was a qualitative, descriptive study with a sample of 15 workers from the household waste collection service of the city of Fortaleza, chosen at random. The results show that the work has a positive meaning for these workers in the three dimensions of analysis, allowing the professional growth, valorization, recognition and self-actualization of the individual. On the other hand, negative relations were found in the contexts of contributory recognition before the society and the autonomy of the worker. In general, the results contribute to a greater understanding of the senses of the work of garis collecting household waste.

Keywords: Sense of Work. Dimensions of the Sense of Work. Garis Collectors.

\section{INTRODUÇÃo}

O lixo pode ser definido como o resíduo sólido descartado pela população e os profissionais responsáveis por sua coleta são chamados, genericamente, de garis. A imagem social desse grupo de trabalhadores, assim como a sua autoimagem são problemáticas do ponto de vista da sociedade, pois ocorre um desprezo que se origina por parte dos próprios profissionais, de sua situação econômica e de trabalho adversa, que dinamicamente interagem com a imagem social da profissão (SANTOS; SILVA, 2011; VELLOSO; SANTOS; ANJOS, 1997).

O contexto do trabalho pode ser afetado pela reestruturação produtiva, pelo conjunto de inovações tecnológicas e sócio-organizacionais, pelo aumento da competitividade entre países e empresas, pela flexibilização das relações de trabalho, dentre outros (TOLFO; PICCININI, 2007). Por sua vez, Artiles (2007) menciona que o campo do significado do trabalho corresponde ao grau de importância que a ele atribuímos bem como aos valores sociais que se adquire por meio da socialização. Esses valores podem influenciar na escolha da profissão e da carreira, no comportamento organizacional, no enfrentamento das condições de trabalho e na satisfação com a atividade específica. Portanto, Morin (2001) considera o sentido daquilo que o indivíduo faz cotidianamente, podendo-se conhecer mais sobre a sua atividade, e isto possibilita que a organização empregatícia alcance a eficácia sem a preocupação de constantes reforços ao trabalhador.

O sentido que as pessoas encontram no seu trabalho depende, muitas vezes, de diversos fatores, como autonomia, reconhecimento, desenvolvimento e crescimento. Entretanto, vale ressaltar que nem sempre as organizações oferecem esses fatores (TOLFO; PICCININI, 2007). O estudo da temática Sentido no Trabalho se dá pela relevância social da atividade executada, pois se refere a um serviço essencial ligado à saúde e ao bem-estar da população. Trata-se, entretanto, de uma atividade considerada insalubre, na forma da legislação vigente, pela exposição da saúde do trabalhador e da coletividade, ao lado de ser realizada de forma árdua e contínua. Apesar da sua importância social, a atividade é, no plano objetivo e subjetivo, indigna, inferior e suja (BORGES; MOURÃO, 2013).

Santos (2009) enfatiza que a incerteza, no caso dos garis, começa na formação da equipe e na divisão dos roteiros de coleta, rompendo o vínculo de posse das condições de trabalho que eles expressam como "meu trecho". Boas e Morin (2016) defendem que o trabalho deve gerar um grau de autonomia, de forma a permitir as pessoas exercerem suas 
atribuições, gerar soluções de problemáticas e ter direito a opinar nas decisões que as afetam. Ademais, autonomia e liberdade podem gerar um ambiente de trabalho participativo e positivo, no qual as pessoas sentem prazer em trabalhar em equipe e também de forma mais independente.

No entanto, pouco se sabe sobre o sentido do trabalho para os garis coletores, tendo em vista que a literatura sobre esse assunto é escassa ou quase inexistente. $O$ presente estudo parte da seguinte questão de pesquisa: qual o sentido do trabalho para os garis coletores de resíduos domiciliares? O objetivo geral, portanto, é investigar os sentidos do trabalho no campo profissional na perspectiva dos trabalhadores garis coletores de resíduos domiciliares. Para tanto, são propostos os seguintes objetivos específicos: (i) analisar o sentido do trabalho sob a dimensão individual; (ii) investigar a dimensão organizacional do sentido do trabalho; e (iii) caracterizar a dimensão social do sentido do trabalho.

A relevância deste estudo se dá devido à representatividade do processo de limpeza urbana dos garis coletores de resíduos domiciliares na sociedade que, apesar de ser considerado desqualificado socialmente (GALDINO; MALYSZ, 2016), é essencial para a limpeza urbana da cidade, para a redução dos impactos socioambientais e para a comunidade em geral. Além disso, dentre as atividades de limpeza urbana, a de coleta domiciliar é considera a mais perigosa, que traz mais riscos à saúde do trabalhador - devido as suas condições precárias (COSTA, 2007) -, e isto sugere um "olhar" mais profundo na perspectiva acadêmica, social e gerencial em relação aos profissionais que as executam, os garis coletores de resíduos domiciliares.

Nesse sentido, pesquisas como esta tornam-se pertinentes para a compreensão do trabalho desenvolvido pelos garis, assim como para subsidiar políticas públicas que possam impactar diretamente na valorização e nas melhorias das condições de trabalho dos profissionais. Espera-se, portanto, que os resultados encontrados possam relevar os sentidos do trabalho dos garis coletores de resíduos.

Na sequencia, procede-se a um aprofundamento teórico sobre as atividades dos garis coletores de resíduos e sobre significado e sentido do trabalho. Após, são descritos os procedimentos de pesquisa, a análise e discussão dos resultados e as considerações finais.

\section{REFERENCIAL TEÓRICO}

\subsection{Atividades dos garis coletores de resíduos}

De acordo com Borges e Mourão (2013), o trabalho é o esforço feito por um indivíduo em um conjunto de atividades para alcançar um objetivo, ou seja, orientadas para um fim. Desta forma, entende-se que o trabalho "[...] é uma atividade que implica o confronto do homem com a natureza, mediado pelo uso de tecnologias e também pelo envolvimento com outras pessoas" (BORGES; MOURÃO, 2013, p. 55-56). As autoras complementam, ainda, que é uma atividade primeiramente direcionada para o próprio sujeito e o alcance de seus projetos e expectativas e a satisfação de desejos. Adicionalmente, para uma matéria prima e um objeto, e por fim para outros, como clientes e colegas de trabalho.

A limpeza urbana passou a ter relevância mundial a partir do ano de 1950, por indução da Organização Mundial de Saúde (OMS) e da Organização Pan-Americana de Saúde 
(OPAS) (SANTOS, 1999). No Brasil, na década de 1970, surgiram os primeiros estudos sobre os trabalhadores da coleta de lixo. Os coletores de resíduos, mais popularmente denominados garis, realizam seu trabalho de uma forma árdua, sujeitos a todos os tipos de intempéries climáticas e exposição contínua a todo tipo de dejeto. A denominação gari surgiu na década de 1940. A empresa "Irmãos Gary" foi a primeira empresa brasileira prestadora de serviços de coleta, transporte e destinação final do lixo. Em função da regularidade do trabalho, os coletores de lixo passaram a ser chamado de garis, até hoje em todo o Brasil (COSTA, 2007; SANTOS, 1999; VELLOSO; SANTOS; ANJOS, 1997).

Santos e Silva (2011) citam que o crescimento populacional, os avanços tecnológicos e o aumento do consumo, ocasionou uma grande quantidade e diversidade de resíduos sólidos (lixo), que demandam tratamento e/ou disposição correta, para evitar problemas ambientais e de saúde pública. Lopes et al. (2012) ressaltam que a atividade do gari coletor está essencialmente relacionada à coleta de lixo e, apesar da sua grande significância social, tende a ser vista como um trabalho "menor", sendo estes profissionais deixados em segundo plano na estrutura social. Outras interpretações relacionadas às atividades dos garis estão nas más condições de trabalho da classe, na remuneração inferior, nas lesões osteomusculares e nos riscos permanentes de contaminação. Tais elementos apontam, contudo, para uma relação entre adoecimento e atividade laboral, na qual a organização do trabalho pode ser um fator nocivo para a saúde (LIMA, 2004).

$\mathrm{O}$ preconceito também está relacionado às atividades cotidianas dos garis, face à carga simbólica do lixo, usualmente carregada de sentimentos negativos como a ojeriza e a repugnância, materializadas na figura do "lixeiro" (LOPES et al., 2012). Porém, na pesquisa realizada pelos autores, os garis relataram que o preconceito vem diminuindo na atualidade e que já são vislumbrados pela sociedade: sentimentos positivos em relação ao trabalho que realizam. O risco social também é ocasionado pela falta de treinamento e orientação, por parte do empregador, e pelo pouco conhecimentos que eles possuem referente a importância da sua função na economia, limpeza e organização da cidade (DIAS et al., 2015). Kuijer, Sluiter e Frings-Dresen (2010) destacam, por sua vez, que são os trabalhadores coletores que contribuem muito para a saúde da população, evitando diversas doenças através da remoção do lixo. $O$ autor, a respeito da saúde dos coletores de lixo, relata que há evidências moderadas que relacionam a ocupação desses indivíduos com os riscos de desenvolver doenças respiratórias e lesões.

Borges e Mourão (2013) afirmam que o risco de uma identificação coesa à sujeira, ao abjeto e à morbidade é grande, e o olhar do outro tende a assimilar o trabalhador ao objeto com o qual trabalha. Como por exemplo, em uma pesquisa realizada por Borges e Mourão (2013), nos cemitérios públicos de Belo Horizonte, em Minas Gerais, os trabalhadores relataram que seus amigos geralmente não sabiam onde eles trabalhavam, pois "Trabalhar em cemitério dá medo nas pessoas, elas se afastam de nós", desta forma, procurando maior valorização, identificam-se como plantonistas de sepultamento, e não coveiros, como são geralmente chamados. Mesmo os profissionais que exerciam atividades administrativas recusavam-se a dizer que trabalhavam em cemitérios, afirmando simplesmente que trabalhavam na prefeitura de Belo Horizonte, pois, segundo um dos entrevistados pelas autoras, "Se digo que trabalho em cemitério, as pessoas vão ficar com nojo de mim. Até em minha casa, a roupa e o sapato que uso para trabalhar ficam do lado de fora para não serem misturados com as outras coisas". 
Mesmo dentre os 'trabalhadores do lixo', constata-se uma distinção de atividades, em que a limpeza, o manejo e a remoção de resíduos sólidos são executados, em geral, por pessoas com menor grau de escolaridade e nível social inferior, estando, em consequência, fadados a exercer as funções mais insalubres e degradantes (BORGES; MOURÃO, 2013). A coleta do resíduo urbano domiciliar da cidade de Fortaleza, Estado do Ceará (CE), utiliza-se de uma empresa concessionária prestadora de serviço terceirizado. As equipes de trabalho são compostas, em geral, por um motorista e três coletores. O motorista tem a função de conduzir o veículo pela rota pré-determinada e acompanhar os coletores de acordo com a velocidade que está sendo realizada a coleta do lixo que está disposto nas calçadas, nos latões ou nas lixeiras suspensas.

$\mathrm{Na}$ cidade de Fortaleza-CE, a coleta é setorizada, dividindo a cidade em vinte e cinco zonas geradoras de lixo que são englobadas pelas sete regionais (I, II, III, IV, V, VI e o Centro). $\mathrm{Na}$ regional Centro a coleta é realizada todos os dias, no período da noite, por conta do grande fluxo de pessoas referente ao comércio. Nas outras regionais a coleta ocorre em dias alternados, sendo segunda, quarta e sexta ou terça, quinta e sábado, nos períodos diurno ou noturno.

\subsection{Significados e sentidos do trabalho}

De acordo com Tolfo e Piccinini (2007), os estudos sobre sentidos e significados do trabalho se acham, em geral, apoiados na perspectiva do indivíduo, a partir de experiências de vida. Os significados no trabalho são também construídos coletivamente, de acordo com um determinado contexto histórico, econômico e social. Logo, os sentidos do trabalho resultam não apenas da apreensão do próprio indivíduo, mas também dos significados coletivos que se transformam no decorrer do tempo, em conformidade com os contextos supramencionados.

Tolfo e Piccinini (2007) ressaltam ainda que o conceito de significado se relaciona com o entendimento ou com a representação social que a tarefa tem para o trabalhador, simultaneamente nos planos individual, do grupo de trabalho ou social, no sentido mais amplo. Como definidores da noção de sentido do trabalho, os pesquisadores do grupo Meaning of Work International Research Team - MOW (1987), após uma pesquisa desenvolvida com amostras significativas em diversos países para identificar as variáveis que explicam os significados que as pessoas atribuem ao próprio trabalho, concluíram além dos significados individual, coletivo e social do trabalho, os fatores utilidade da tarefa executada para a organização contratante, a auto realização e a satisfação individual, ao lado do sentimento de crescimento pessoal e profissional, da liberdade e da autonomia para a realização da atividade. Por se tratar de um construto multidimensional, compreende-se como uma interdependência entre os termos.

Referida constatação está apoiada na ideia de que a organização não deve expor os indivíduos a trabalhos repetitivos, mas prover o trabalho de autonomia e da possibilidade de tomar decisões (ENRIQUEZ, 1999). Para Dejours (1992), Morin (2001) e Antunes (2015), o reconhecimento dos indivíduos no trabalho é determinante para a construção de uma identidade pessoal e social, por meio da realização das tarefas em que utiliza seus conhecimentos e sua autonomia. Portanto, Viana (2008) considera que, na sociedade contemporânea, grande parte dos indivíduos é mais envolvida com o trabalho do que 
qualquer outra atividade, tornando-o essencial para a realização do sujeito. Para conhecer o sentido que os trabalhadores dão às atividades que realizam, é necessário considerar a relação que eles mantêm com as atribuições que realizam e com a organização do trabalho. São importantes as informações sobre suas histórias de vida e subjetividades (MORIN, 2001).

O trabalho é considerado o centro da vida das pessoas, "[...] é a essência da natureza humana, proporcionando-nos não apenas os meios materiais para viver, mas também nossa própria realização pessoal e nossos vínculos sociais" (BERNAL, 2010, p. 15). Além disso, a atual representação do trabalho para o sujeito deriva do capitalismo. Por sua vez, Clot (2006) ressalta que atribuir ao trabalho a importância apenas em termos econômicos, demonstra uma falta de entendimento do seu papel no desenvolvimento das pessoas. De acordo com este autor, o trabalho satisfaz várias necessidades psicológicas, fornecendo referências de senso de identidade, tempo, autoestima e status da pessoa na sociedade.

Antunes (2015) afirma que, para existir uma vida com sentido fora do trabalho, é necessária uma vida dotada de sentido dentro do trabalho. Destaca ainda que não é possível associar trabalho assalariado, ludibriado e estranhado com o tempo, com sentimentos de prazer, realização e pertença que trazem sentido para a vida. Portanto, o indivíduo que não encontra sentido e realização em seu trabalho diário, dificilmente o encontrará fora dele, uma vez que esta atividade invade todas as esferas da sua vida. O sentido do trabalho pode ser visto, em uma abordagem mais gerencial, como a compreensão dos empregados com a atividade que executam no trabalho assim como a importância do que eles realmente fazem (WRZESNIEWSKI; DUTTON; DEBEBE, 2003). Esses autores defendem ainda que os funcionários são movidos a alcançar um sentido para seus esforços. Estudos demonstram que a estruturação do sentido do trabalho fica estável ao longo do tempo (HARPAZ; FU, 2002) e está relacionado com a maneira como as pessoas entendem sua experiência nas instituições em que trabalham (CARTWRIGHT; HOLMES, 2006).

Na sociedade atual torna-se comum a forma de trabalho alienada e sem sentido, na qual o trabalho deixa de ser fonte de realização e passa a ser fonte de sofrimento e adoecimentos diversos (ANTUNES; ALVES, 2004; ANTUNES, 2015; CLOT, 2006; ENRIQUEZ, 1999; ORGANISTA, 2006; ROSSO; DEKAS; WRZESNIEWSKI, 2010; TOLFO et al., 2011; TOLFO; PICCININI, 2007). Dos vários aspectos relacionados ao sentido do trabalho, há em comum as crenças de uma pessoa sobre a função que o trabalho exerce na sua vida, que é atingida pelo cenário social no qual vivem os trabalhadores. Pratt e Ashforth (2003) sugerem uma forma de distinção entre sentido do trabalho e sentido no trabalho, no qual o primeiro está relacionado com características do trabalho e o segundo com relações estabelecidas no trabalho. Os autores evidenciam a suposição de que o sentido que a pessoa dá ao seu trabalho e o seu ambiente de trabalho está ligada com a sua própria identidade, essa distinção entre sentido no/do trabalho, permite ao trabalhador responder às seguintes perguntas: o que eu faço? Quem sou eu? Por que estou aqui?.

\section{METODOLOGIA}

Este estudo guia-se pelo paradigma interpretativista, tratando-se de uma pesquisa qualitativa, de natureza descritiva. Toma-se como base o modelo proposto por Oliveira et al. (2004), o qual segue a mesma linha que Morin, Tonelli e Pliopas (2007). Dessa forma, foi priorizada a percepção dos indivíduos em contexto similar ao desta pesquisa, a partir da 
relação do trabalhador com a organização empregadora, com a sociedade e da sua autopercepção do sentido do trabalho. Oliveira et al. (2004) utilizaram estas dimensões, subdivididas em categorias e qualificações de trabalho com sentido e sem sentido. Para isto, este estudo valeu-se de entrevista semiestruturada com indivíduos que manejam diretamente a coleta de resíduos domiciliares.

A amostra foi composta por 15 trabalhadores garis coletores que são funcionários da empresa responsável pela coleta de resíduos domiciliar em Fortaleza-CE. Os entrevistados foram escolhidos de modo aleatório pelo supervisor da área de operação, por conveniência e de acordo com a disponibilidade dos mesmos, até que se obtivesse saturação dos dados. Os entrevistados foram identificados por "Trabalhador", seguido pela numeração equivalente à ordem pela qual as entrevistas foram realizadas.

A coleta de dados ocorreu por meio de entrevistas, sendo utilizado o roteiro de entrevista semiestruturada, acompanhada de gravador de voz. Oito das entrevistas foram realizadas no dia 13/10/2016 e sete no dia 19/10/2016, com duração de quinze minutos e quarenta e quatro segundos, em média, para cada entrevistado. A primeira parte do roteiro de entrevistas compreendeu perfil sociodemográfico dos entrevistados; e o segunda parte abordou as categorias das dimensões individual, organizacional e social.

Dessa forma, as três categorias de análise, dimensão individual, organizacional e social dos sentidos do trabalho, estão caracterizadas a partir das categorias de análise definidas as respectivas unidades de contexto e unidades de registro. Para cada unidade de registro do trabalho com sentido, existe uma unidade de registro do trabalho sem sentido, diretamente excludente (QUADRO 1).

Quadro 1 - Categorias, unidades de contexto e de registro: trabalho com sentido e sem sentido

\begin{tabular}{|c|c|c|c|}
\hline $\begin{array}{l}\text { Categorias de } \\
\text { análise }\end{array}$ & $\begin{array}{c}\text { Unidades de } \\
\text { contexto }\end{array}$ & $\begin{array}{c}\text { Unidades de registros } \\
\text { com sentido }\end{array}$ & $\begin{array}{c}\text { Unidades de registros } \\
\text { sem sentido }\end{array}$ \\
\hline \multirow{11}{*}{$\begin{array}{l}\text { Dimensão } \\
\text { Individual }\end{array}$} & \multirow{2}{*}{ Coerência } & Identificação & Não Identificação \\
\hline & & Importância & Não Importância \\
\hline & \multirow[t]{2}{*}{ Alienação } & Clareza & $\begin{array}{l}\text { Não há clareza quanto ao objetivo } \\
\text { do trabalho }\end{array}$ \\
\hline & & Objetivo do trabalho & Desconhece o objetivo do trabalho \\
\hline & \multirow{2}{*}{ Valorização } & Valorização do trabalho & Não valorização do trabalho \\
\hline & & Reconhecimento do trabalho & Não reconhecimento do trabalho \\
\hline & Prazer & Gostar do trabalho & Não gosta do trabalho \\
\hline & \multirow{2}{*}{ Desenvolvimento } & Desenvolvimento pessoal & Não há desenvolvimento pessoal \\
\hline & & Crescimento profissional & Não há crescimento profissional \\
\hline & \multirow{2}{*}{$\begin{array}{l}\text { Sobrevivência e } \\
\text { Independência }\end{array}$} & Retorno financeiro & Não há retorno financeiro \\
\hline & & Necessidades básicas & Não atende às necessidades básicas \\
\hline \multirow{3}{*}{$\begin{array}{c}\text { Dimensão } \\
\text { Organizacional }\end{array}$} & \multirow{2}{*}{ Utilidade } & Contribui com a empresa & Não contribui com a empresa \\
\hline & & Atende às expectativas & Não atende às expectativas \\
\hline & Organização do & Diversificado & Rotineiro \\
\hline
\end{tabular}




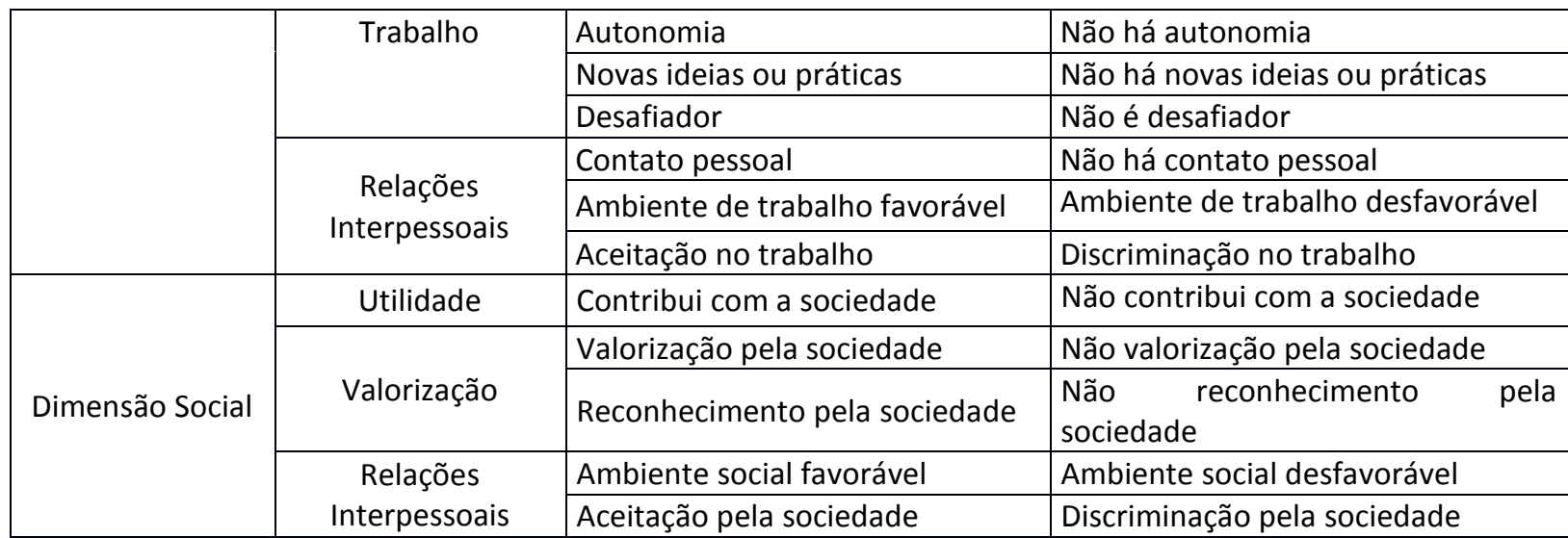

Fonte: Adaptado por Canholi Júnior et al. (2016), a partir de Oliveira et al. (2004).

As entrevistas foram transcritas e organizadas por meio dos softwares Express Scrib (Express Scrib, V 5.5 - conversão de voz em dados digitalizados) e Atlas.ti (Atlas.ti, V 6.0). Para o tratamento das transcrições ocorreram inferências e interpretações para codificação do texto, buscando-se relacionar os discursos dos entrevistados com as categorias de estudo.

\section{ANÁLISE E DISCUSSÃO DOS RESULTADOS}

\subsection{Dados sociodemográficos}

$\mathrm{Na}$ empresa investigada não foram encontradas mulheres coletoras de resíduos domiciliares, todos os participantes são do sexo masculino, sendo $73 \%$ casados e $27 \%$ solteiros, não sendo apresentado nenhum viúvo ou divorciado. A média de tempo de experiência na área de coleta de resíduos domiciliar dos participantes é de quatro anos e dois meses, porém observou-se grande amplitude no tempo de experiência. Há dois participantes com menor tempo de experiência (seis meses), enquanto que aquele com maior experiência trabalha há 20 anos como gari coletor.

Em relação à idade média dos participantes, verificou-se 32 anos, ressaltando-se a variação entre o mais novo com 19 anos e o mais velho com 49 anos. Outro dado que teve relevância refere-se ao fato de que todos os trabalhadores entrevistados possuem a carteira assinada com o valor de $\mathrm{R} \$ 920,00$ reais, mais benefícios como, por exemplo, vale transporte e plano de saúde.

\subsection{Dimensões do sentido do trabalho}

No tocante à análise e discussão dos resultados, destacam-se as categorias de análise por meio das dimensões individual, organizacional e social do sentido do trabalho, realizada com a utilização da ferramenta Network View.

Para as unidades de contexto, os códigos que representaram as unidades de registro foram relacionados aos que representaram as unidades de contexto por meio de setas. Cada código foi indicado com um par ordenado de dois números, como código $\{x-y\}$, nos quais o " $\mathrm{x}$ " representou o número de citações ao qual o código foi relacionado, e o " $\mathrm{y}$ " representou o número de outros códigos aos quais ele está ligado. As descobertas com origem nos dados 
desta pesquisa foram relacionadas ao referencial teórico expresso, permitindo o alcance dos objetivos propostos.

\subsubsection{Dimensão individual do sentido do trabalho}

O primeiro objetivo específico buscou a dimensão individual do trabalho, destacando, portanto, aspectos relacionados à coerência, alienação, valorização, sobrevivência e independência, desenvolvimento e prazer (FIGURA 1).

Figura 1 - Dimensão individual do trabalho

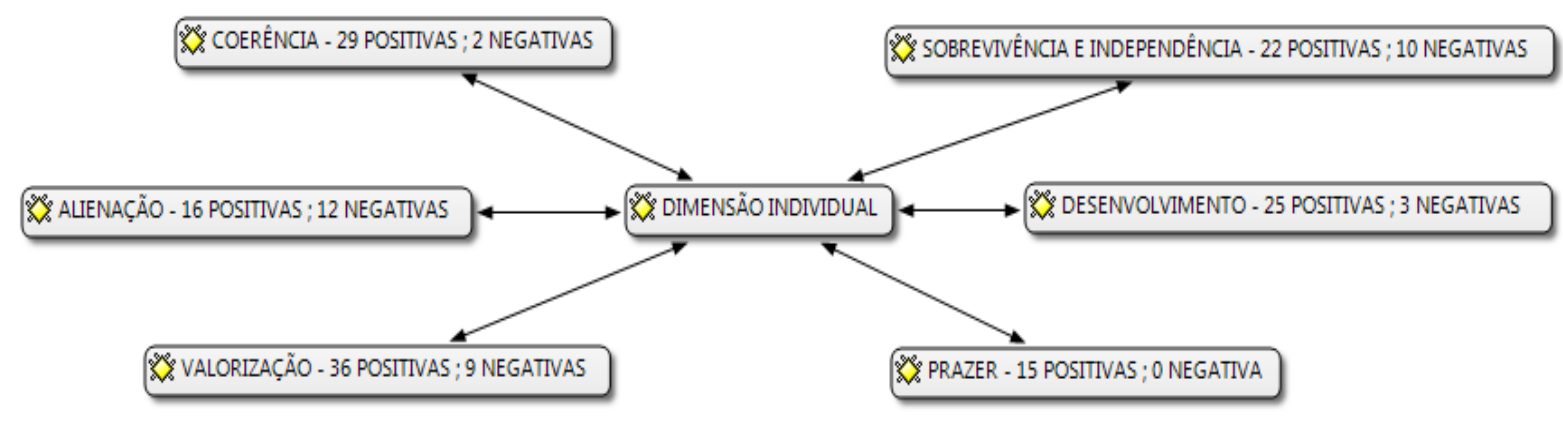

Fonte: Elaborada pelos autores.

No código 'Coerência', os entrevistados, em sua quase totalidade (29 afirmações positivas contra apenas 2 negativas), expressaram o alinhamento do trabalho com os valores e as crenças pessoais. Como é descrito a seguir em algumas citações dos trabalhadores:

Sim [considera útil], porque eu gostei de entrar aqui para fazer esse serviço. Antes eu trabalhava como pedreiro, trabalhava na construção civil e deixei para trabalhar aqui de gari coletor. [...] [É importante] Com certeza! Porque é com esse trabalho que eu tô dando de comer a minha filha. (Trabalhador 1).

No começo eu não me identifiquei muito não. Na verdade, eu vim pra cá pra passar só um ano, pra adquirir experiência, sei lá! Mas hoje eu me habituo bem, eu me identifico muito com o meu trabalho. [...] É importante porque é de onde eu tiro o meu sustento, né! Meu e da minha família. Eu acho muito importante. Porque se você não se identificar com seu trabalho, você trabalha sem vontade, sem gosto! (Trabalhador 14).

No quesito 'Alienação', em contrapartida, as menções negativas (12) englobando o nível de conhecimento do processo de trabalho, do seu produto final e dos impactos das suas atividades, evidenciam um domínio superficial desses tópicos, que conta com 16 menções positivas. Em alguns casos, desconhecem o teor do trabalho que executam, como é colocado pelo Trabalhador 9: "Não sei porque estou fazendo. É uma função que quando você entra na empresa já tem aquela função." Ou ainda, como comenta o Trabalhador 10: "Meu trabalho é útil, porque sei lá!". Percebeu-se nas falas que os mesmos entendem 
apenas sobre a tarefa executada pontualmente, apesar de apresentarem um conteúdo substancial na descrição da utilidade da atividade, muitos ainda citaram ser por obrigação. Por exemplo, as falas do Trabalhador 11: "Sei (por que o trabalho é útil). Para benefício da cidade, da população e até pra mim mesmo que tá exercendo o trabalho. Trabalho pra todo mundo."; e do Trabalhador 12: "Eu acho que é útil porque é uma necessidade diária, né! A gente tem que tá ali todo dia, todo dia a gente tem que tá. A gente ficou 4 horas [sem coletar] e ficou meio mundo de coisa, imagina se a gente fica um dia completo."

$\mathrm{Na}$ unidade 'Valorização', 75\% dos entrevistados se considera valorizado e reconhecido por parte da empresa, particularmente na maneira como os supervisores os tratam, mas também no salário e nos benefícios que recebem, além da possibilidade de evolução funcional na empresa. É o que menciona, por exemplo, o Trabalhador 14: "Com certeza! Até pela oportunidade que a empresa nos deu aqui, de concluir o ensino médio. Dá oportunidade pra você crescer também como motorista, como já teve vários aqui que era gari, motorista e tem até analista. Ela dá oportunidade."

Diferentemente do que pode sugerir o senso comum, registra-se no código 'Prazer' (no trabalho) uma unanimidade absoluta. No quesito 'Desenvolvimento', também, há intensa menção positiva de $89 \%$ dos trabalhadores, destacando as alternativas de crescimento e ascensão funcional e aprendizagem.

No requisito 'Sobrevivência e Independência', entretanto, representado pelo retorno financeiro diante das necessidades do dia, apenas $68 \%$ afirmam positividade, evidenciando um forte vetor de depreciação para a manutenção da dimensão individual do trabalho. 0 retorno financeiro frente às necessidades básicas do indivíduo (e da sua família) é um tradicional evidenciador de justiça à especificidade do trabalho, do seu grau de dificuldade e do custo benefício de se trabalhar na coleta de resíduos domiciliar. Na leitura positiva, recolheram-se, por exemplo: "Com certeza! Muito melhor do que as outras anteriores que eu já trabalhei. Bastante mesmo!" (Trabalhador 8); "Como eu sou solteiro, sim! Até sobra. Tô ajudando a minha mãe que mora aqui comigo, ai mando dinheiro para as minha irmãs que ficaram no interior. Ai tá bom demais." (Trabalhador 11). Em contrapartida, há colocações em sentido oposto: "Não. Sempre fico devendo alguém. Eu saio pagando, mas sempre falta alguma coisa." (Trabalhador 9); "Não. Na realidade tá muito pouco. Deveria ser mais." (Trabalhador 13); "Não. Falta, por conta do nosso serviço eu creio que falta" (Trabalhador 14).Todos os trabalhadores ganham o mesmo valor de salário.

O trabalho está visivelmente ligado a ideia de emprego e ao salário que ele proporciona para suprir as necessidades básicas, permite um sentimento de segurança e possibilita ser autônomo e independente. Precisamente, na maioria das vezes, associamos o salário a elementos de prestígio, mas na verdade está claramente associado a segurança e a independência (ARTILES, 2007; MORIN, 2001; TOLFO; PICCININI, 2007).

$\mathrm{Na}$ dimensão individual, os entrevistados expressaram que o trabalho que faz sentido é coerente com seus valores e crenças. Segundo Tolfo e Piccinini (2007), na dimensão individual um trabalho que faz sentido pode ser identificado com os valores éticos e morais da pessoa, possibilita valorização, desenvolvimento e crescimento, é prazeroso, faz com que a pessoa saiba o que está realizando e acreditar no que está fazendo. O fator financeiro, apesar de referido, torna-se apenas complementar e não essencial para tornar o trabalho com sentido. Porém, quando o trabalho entra em choque com os valores pessoais do indivíduo, ou quando este não acredita na proposta apresentada, o trabalho tem tendência 
a ser fonte de sofrimento, perdendo o sentido.

\subsubsection{Dimensão organizacional do sentido do trabalho}

O segundo objetivo específico explorou a dimensão organizacional, avaliando aspectos relativos à utilidade, à organização do trabalho e às relações interpessoais da atividade que executam.

Figura 2- Dimensão organizacional do trabalho

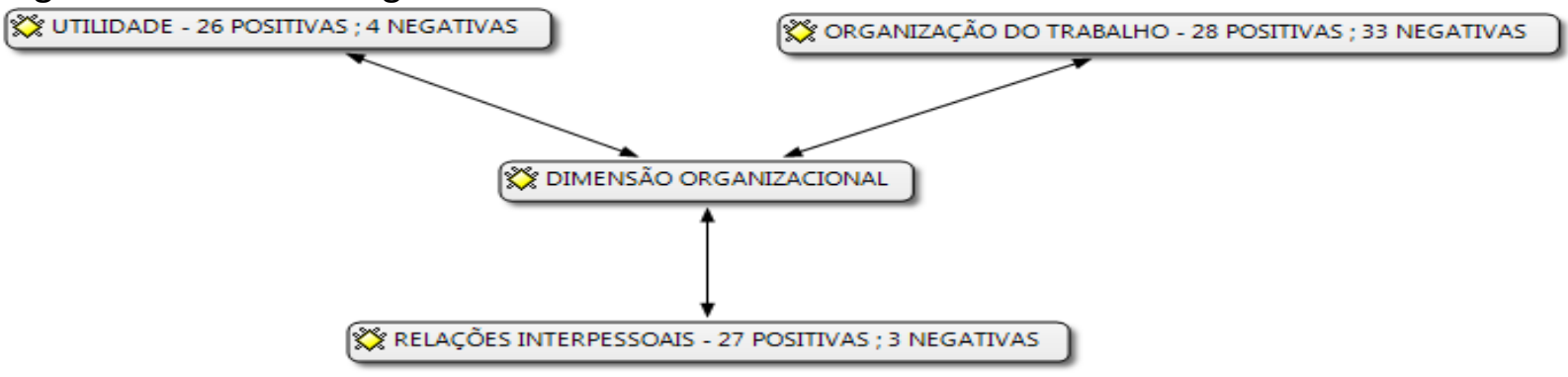

Fonte: Elaborada pelos autores.

No código 'Utilidade' trata-se da contribuição e do atendimento às expectativas da empresa, bem como suas versões negativas, na interpretação dos entrevistados. Observouse, em quase sua totalidade (26 afirmações positivas, contra apenas 4 negativas), que os entrevistados consideram que seu trabalho contribui para a empresa e demonstraram acreditar que atendem às expectativas da empresa, tornando-se, assim, um trabalho com sentido, pois possui alguma utilidade, conforme as citações seguintes: "Acho que atende. Se não atendesse eles já tinha botado muita gente pra fora, né. Então eu acho que atende a necessidade da empresa." (Trabalhador 4); "Com certeza ela considera o nosso trabalho útil. Eles reconhecem o esforço da gente. Nós somos o alicerce da empresa." (Trabalhador 11). Percebe-se, ainda, em respostas negativas, em algumas falas sobre "utilidade", que o trabalhador relatou o fato de ser um trabalho pesado e que nem sempre eles estão $100 \%$ para a execução da atividade, conforme menciona o Trabalhador 13: "(É útil para a empresa) Se eu tiver na minha saúde normal, sim! Mas se eu não tiver, não!”. Essa constatação também foi feita em outra entrevista:

Entre certos pontos sim e outros não. Porque é assim, você sair todo dia, todo dia para aquela rotina, você nunca tá $100 \%$. Se você melhorou hoje, amanhã você pode ter uma contusão, alguma coisa e você não atende as necessidades da empresa. $\mathrm{E}$ as vezes a empresa cobra, entendeu! E nunca a gente tá $100 \%$ toda vida [...]. (Trabalhador 14).

Na unidade de contexto 'Organização do Trabalho' foi possível constatar que existem oito unidades de registro, que indicam o trabalho com ou sem sentido, de acordo com a diversificação, os desafios, as novas ideias e práticas e a autonomia para com o trabalho, sempre sob a percepção dos entrevistados.

As perguntas formuladas com o intuito de identificar se os trabalhadores da coleta de resíduos possuem um trabalho com sentido foram: $\mathrm{O}$ seu trabalho é rotineiro ou repetitivo? 
Você tem autonomia no seu trabalho? Sua atividade é pré-determinada? Você tem liberdade de sugerir uma ideia ou uma nova prática e ela ser utilizada pela empresa? Você acha seu trabalho difícil? Desafiador?

O código 'Organização do Trabalho' tem a maior incidência de menções negativas, suplantando as menções positivas e em aparente contradição com os achados da dimensão individual. Neste quesito, $80 \%$ dos entrevistados consideram desafiador: "É desafiador! É perigoso! E os riscos tem de tudo: quebrar uma perna; quebrar um braço; cair do caminhão e o carro passar por cima... Porque a gente anda atrás, pendurado, né!? E principalmente doença. No lixo tem de tudo" (Trabalhador 1).

As dificuldades e os desafios também foram relatados por alguns trabalhadores:

Muito [desafiador]. Não é fácil, porque tem dia que a gente não consegue
nem levantar, porque seu físico tá tão cansado que: 'oh meu Deus, mais um
dia!' É um trabalho árduo, difícil e também estamos arriscados a pegar
enfermidades, doença incurável, por isso que temos esses $40 \%$ (de
insalubridade). A nossa coleta domiciliar, tudo que você imaginar a gente
pega, desde fezes, rato, é muito perigoso! Teve pessoas que já faleceram,
porque pegaram uma enfermidade e não se cuidaram (Trabalhador 2).
É difícil, desafiador e perigoso. É difícil, porque nem todo dia a gente tá
$100 \%$. Porque devido a semana puxada, se torna mais difícil, mais
cansativo. E perigoso porque também às vezes muito carro e tem carro que
não respeita. Nós tamo aqui com o lixo na rua e vai passar, eles não
respeitam e passam por cima. Graças a Deus tem gente consciente, mas
tem uns, é difícil! (Trabalhador 7).

Ainda assim, 20\% dos trabalhadores consideram o trabalho fácil, embora desafiador: "Num é que seja difícil, mas é preciso ter coragem. Desafiador ele é. Difícil ele não é não! Ele é fácil, mas se não tiver coragem para exercer é mesmo que nada!" (Trabalhador 3).

Ainda sobre o código 'Organização do Trabalho', há menção relevante nas unidades de contexto 'Autonomia' e 'Novas Ideias e Práticas', que aparentemente deveriam ser similares em seus episódios, pois em geral ganham força quando há abertura por parte da empresa. Assim, o contexto 'Autonomia' aparece em uma única citação, correspondendo a cerca de $6 \%$ dos eventos. A unidade 'Novas Ideias e Práticas', por outro lado, aparece em cerca de $86 \%$ de ocorrências, como é possível constatar nos trechos a seguir:

Não! É pré-determinada. [...] Aqui na empresa a gente tem essa possibilidade de dar ideia, comentar. Nem que não seja assim do jeito que eles querem. Naquela hora eles, não assim é melhor e não dão o braço a torcer, mas depois voltam atrás e recorrem a nossa conversa. Principalmente da ideia de trabalho. Porque se for do jeito deles a gente roda muito. Roda, roda, cansa e faz, mas demora mais. E se for do nosso jeito é mais rápido. (Trabalhador 1).

Depreende-se das citações que autonomia para os trabalhadores está relacionada com autoridade ou com tomada de decisão pelos cargos hierarquicamente superiores. Apesar de predominar esse entendimento, foi possível identificar em várias falas a autonomia sendo exercida pelos trabalhadores, inclusive sugerindo novas práticas e ideias. 
Assim, explica-se porque a unidade de registro 'Organização do Trabalho' apresenta números negativos superior aos positivos, tendo em vista que esta era a categoria que apresentava maior número de unidades de registro e também evidenciou uma subjetividade de interpretação de conceitos como autonomia, rotina, desafio e criatividade.

O ambiente organizacional não foi considerado desfavorável em nenhuma das entrevistas. Em $100 \%$ dos casos foi considerado favorável, o que contribui para um trabalho com sentido. Já no que diz respeito às relações interpessoais e aos eventos de aceitação, ambiente macro da empresa de coleta, o trabalho tem sentido em $86 \%$ dos relatos feitos pelos entrevistados.

$\mathrm{Na}$ dimensão organizacional, para um trabalho fazer sentido, ele deve atingir resultados, ser útil para a empresa ou para o grupo. Nesta dimensão, o trabalho que faz sentido permite que o trabalhador tenha autonomia, possa exercer sua criatividade e pensamento. Morin (2001) e Tolfo e Piccinini (2007) salientam que a existência de desafios na execução da atividade é um fator relevante. Entende-se, portanto, que um trabalho com sentido permite que o trabalhador possua autonomia e consiga exercer sua criatividade. Os desafios encontrados na execução desta atividade tornam-se relevantes e a partir do momento que se torna rotineiro, burocrático, operacional e incapaz de instigar seu executor, influencia diretamente na definição de um trabalho que faz ou não sentido para o sujeito. Nesta dimensão, um trabalho com sentido é narrado como realizado em um ambiente agradável, onde as relações interpessoais são positivas e proporciona relações construtivas. Como parâmetro geral, na dimensão organizacional do trabalho, foi demonstrada que para o trabalho fazer sentido para o trabalhador, este deve alcançar resultados, ter valor para a empresa ou para o grupo e ter importância para a empresa.

\subsubsection{Dimensão social do sentido do trabalho}

O terceiro objetivo específico explorou a dimensão social do sentido do trabalho, por meio das unidades de contexto utilidade, valorização e relações interpessoais, de acordo com a Figura 3.

Figura 3 - Dimensão social do trabalho

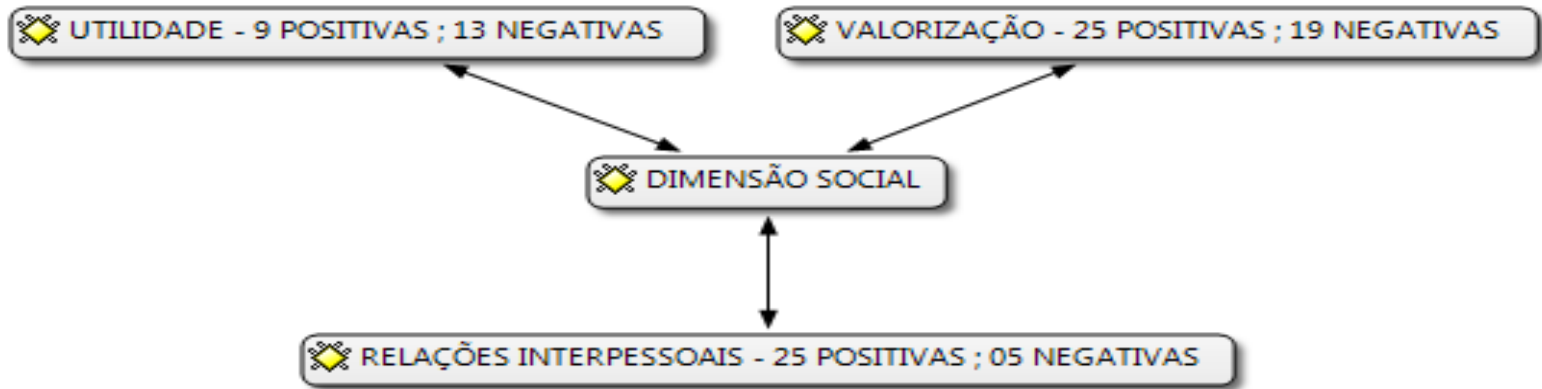

Fonte: Elaborada pelos autores.

Em relação à 'Utilidade' para a sociedade, temos um percentual de $41 \%$ das citações positivo contra $59 \%$ negativo, sugerindo dissociação de sentido do trabalho na dimensão social. É possível perceber que os trabalhadores buscar amenizar os relatos, pela ausência de generalizações, conforme os seguintes relatos: "Poucos entendem (a contribuição). A 


\section{O SENTIDO DO TRABALHO DOS GARIS COLETORES DE RESÍDUOS DOMICILIARES}

maioria critica, mas tem uns que chamam a gente e conversam com a gente, agradecem e a gente recebe elogio." (Trabalhador 5); "São poucos que entendem, viu (a contribuição)! Tem gente que a gente tá limpando aqui e deixa bem limpinho. Aí o caba chega com uma saca e joga no chão. Tá lá a caixa pra colocar, mas o caba chega e bota no chão." (Trabalhador 9).

Além desses, outros trabalhadores também ponderaram que:

Uns entendem e outros não entendem (a contribuição). Eles acham que a gente é burro de carga e pode levar tudo. Mas a gente não pode levar tudo, a gente só leva aquilo que é determinado a orientação da empresa. São pessoas que não entendem que se não tivesse essa coleta, não teria essa limpeza e a esculhambação ia ser grande, então são poucos os que dão valor ao nosso trabalho (Trabalhador 2).

Assim como a unidade de registro 'Valorização' do sentido do trabalho na dimensão individual, esta unidade possui a mesma nomenclatura, porém com outra perspectiva, pois busca identificar o sentido do trabalho ligado à valorização e ao reconhecimento do trabalho pela sociedade. A unidade apresentou a maioria de indicativos positivos (25), conforme colocação a seguir:

Sim valoriza. Porque ela sabe que é pesado. Graças a Deus a população ajuda, tem consciência do nosso trabalho. Teve uma vez, aqui no (bairro) Passaré que um senhor, era no final do ano, ai ele deu um agradozinho a gente e ainda deu um bilhete agradecendo, achando maravilhoso, que aquilo ali ele achava bonito nós trabalhando ajudando a população (Trabalhador 7).

No que se refere às 'Relações Interpessoais' que ocorrem fora da empresa, verificouse 25 afirmações positivas e apenas 5 negativas. Constata-se, portanto, que em $83 \%$ das citações, obtiveram-se respostas que indicavam um trabalho com sentido, com 25 menções e 5 referências à discriminação e nenhuma ao ambiente social desfavorável, portanto, 17\% das citações não apresentam contribuição a um trabalho com sentido. O seguinte trecho exemplifica esse resultado:

Sabem sim. No começo eu me senti com receio, mas depois eu quer saber de uma coisa: é daqui que eu tiro o pão pra minha família e se não fosse daqui, onde era que eu poderia está agora nesse momento? Poderia até tá desempregado, mas querendo tá no lugar, junto dos meus colegas e hoje todo mundo sabe que eu trabalho aqui. $E$ às vezes tem alguns deles que mandam até currículo por mim, pelas coisas que eu falo, dos benefícios que a empresa oferece e eles dizem: "é realmente onde você tá ai é um pouco puxado, mas os benefícios também ajuda você a se aliviar também do cansaço. [...] Não (existem pessoas que tratam diferente). Só no começo mesmo. Perguntaram: é mesmo? Como é que tu aguenta aquela catinga? .Mas isso ai é supérfluo, no cotidiano você vai se acostumando. Quando tá mais cruel mesmo é quando a pessoa acumula lixo de um dia pro outro, que não coloca no dia da coleta, coloca no outro dia, ai sim! Aí é que rola mais, mas não é essas coisas toda não que o povo diz que é. (Trabalhador 8). 
Na dimensão social do trabalho, um trabalho com sentido é entendido como sendo capaz de ser útil e valorizado, mas também contribuir para o desenvolvimento social. Desta forma, comparando aos aspectos de utilidade, valorização e relações interpessoais analisados anteriormente.

Diante disso, percebe-se que a dimensão social tem maior amplitude, pois o indivíduo se refere ao trabalho como elemento contributivo não só para ele ou para empresa, mas perante a sociedade em geral. A partir do momento em que o trabalho não contribui e deixar de trazer benefícios, não há sentido no trabalho.

\section{CONSIDERAÇÕES FINAIS}

Quanto ao objetivo geral do estudo, constatou-se uma significativa unidade nas percepções dos trabalhadores entrevistados, conduzindo, portanto, ao entendimento de que os trabalhadores percebem sentido e se identificam com o trabalho que realizam, mas que o fenômeno pode ser explicado de maneira não homogênea, uma vez que parece se apoiar, conforme demonstrado, principalmente na dimensão individual, de maneira afirmativa mas menos intensa na dimensão organizacional e com pouca intensidade na dimensão social.

O primeiro objetivo específico propôs analisar o sentido do trabalho sob a dimensão individual. $O$ estudo permitiu evidenciar como significativas para o sentido do trabalho da categoria ocupacional: coerência, alienação, valorização, prazer, desenvolvimento e, sobrevivência e independência. Em consequência, constatou-se que o trabalho tem sentido porque é realizado de acordo com os valores pessoais de quem o executa, consideram prazeroso, além de promover o desenvolvimento e a valorização das pessoas, possibilitando a sobrevivência e a independência, além de promover a realização e a satisfação do trabalhador.

Em relação ao segundo objetivo específico, investigar a dimensão organizacional do sentido do trabalho, foram definidas três unidades de contexto para estruturar a análise: utilidade, organização do trabalho e relações interpessoais. O sentido no trabalho desses trabalhadores ficou demonstrado na preocupação em atender aos interesses e às necessidades da organização, agregando valor e satisfazendo as expectativas da mesma. Adicionalmente, houve o fato da atividade evidenciar a não autonomia dos trabalhadores, mas com destaque para as oportunidades de crescimento proporcionadas pelo empregador.

No tocante ao terceiro objetivo específico, que buscou investigar a dimensão social do sentido do trabalho, as unidades de contexto utilidade, valorização e relações interpessoais abrange os pontos que se relacionam contribuição do trabalho para a sociedade e a percepção de ser ou não valorizado por esta. A dimensão social também abordou a qualidade das relações interpessoais dos trabalhos com a sociedade. $O$ estudo evidenciou o não reconhecimento da contribuição do trabalho realizado, na visão dos respondentes. Foram verificadas também algumas citações que indicam discriminação pela sociedade, causada pelo tipo de atividade executada pelo entrevistado.

Embora tenha segmentado os sentidos do trabalho em três dimensões, elas apresentam uma íntima relação, sendo necessário para cada indivíduo que várias categorias sejam contempladas para que o mesmo consiga atingir sua satisfação pessoal e profissional, seja pelos fatores individuais, organizacionais ou sociais de seu trabalho. Assim, não apenas 
o desenvolvimento de fatores pessoais, organizacionais ou sociais lhe permitirá encontrar um trabalho com mais sentido, e sim a soma das características encontradas em diversas categorias de análise, unidades de contexto e de registro e a relação que se estabelece entre si.

O estudo aqui apresentado contribui para o melhor entendimento de como o trabalho tem sido visto na sociedade contemporânea, destacando-se sua importância e como este se relaciona com a vida dos indivíduos analisados. Porém, a pesquisa realizada apenas com este grupo apresenta limitações que devem ser destacadas. As conclusões deste estudo não podem ser generalizadas, pois estão relacionadas a características particulares dessa organização e desses trabalhadores. A realização do mesmo com profissionais de uma categoria específica limitou a análise da visão desse grupo e também apresentou uma reduzida variedade nas respostas encontradas, indicando uma grande identidade na sua forma de pensar dos entrevistados e, consequentemente, resultados mais concisos. Não foi encontrada diferença nas respostas quanto à idade ou ao tempo de atuação profissional e as respostas às entrevistas foram muito similares, tornando a análise mais objetiva, dificultando maior aprofundamento.

Os resultados encontrados apontam para uma grande unidade na forma de pensar dos trabalhadores garis entrevistados. Nesse sentido, este estudo, ao explorar realidade de trabalho pouco relacionadas com as tendências tecnológicas da economia pós-industrial e por tratar de segmentos relativamente pouco valorizados socialmente, como os garis coletores, permite um olhar diferenciado sobre a realidade e sobre as evoluções do trabalho na sociedade contemporânea. Logo, sugere-se para estudos futuros a realização desta pesquisa em outros estados e com outros garis coletores de resíduos domiciliares, com o intuito de comparar o sentido do trabalho entre garis coletores de resíduos domiciliares de diferentes realidades.

\section{REFERÊNCIAS}

ANTUNES, R. Os sentidos do trabalho: ensaio sobre a afirmação e a negação do trabalho. Boitempo Editorial, 2015.

ANTUNES, R.; ALVES, G. As mutações no mundo do trabalho na era da mundialização do capital. Educação \& Sociedade, v. 25, n. 87, 2004.

BERNAL, A. O. Psicologia do trabalho em um mundo globalizado. Porto Alegre: Artmed, 2010.

ARTILES, A. M. Manual de la sociología del trabajo y de las relaciones laborales. Delta Publicaciones, 2007.

BOAS, A. A. V.; MORIN, E. M. sentido do trabalho e fatores de qualidade de vida no trabalho: a percepção de professores brasileiros e canadenses. Revista Alcance (Online), v. 23, n. 3, p. 272, 2016.

BORGES, L. O.; MOURÃO, L. O trabalho e as organizações: atuações a partir da psicologia. 
Porto Alegre: Artmed, 2013.

CANHOLI JÚNIOR, C.; LIMA, T. C. B. ; LIMA, M. A. M. ; VIANA, L. M. M. Sentidos do trabalho para trabalhadores do saneamento básico. Anais... EnANPAD XL Encontro da ANPAD Associação Nacional de Pós-Graduação e Pesquisa em Administração. Costa do Sauípe, Bahia, 2016.

CARTWRIGHT, S.; HOLMES, N. The meaning of work: The challenge of regaining employee engagement and reducing cynicism. Human Resource Management Review, Amsterdam,v. 16, n. 2, p. 199-208, 2006.

CLOT, Y. A função psicológica do trabalho. Petrópolis: Vozes, 2006.

COSTA, M. A. Condições de trabalho dos coletores de lixo domiciliar, no município do Rio de Janeiro. 2007. Tese de Doutorado. Dissertação (Mestrado em Engenharia Ambiental) da Universidade Estadual do Rio de Janeiro, Rio de Janeiro.

DEJOURS, C. A loucura do trabalho: estudo de psicopatologia do trabalho. 5. ed. São Paulo: Cortez, Oboré, 1992.

DIAS, A. G.; MATOS, R. F.; BRAGA, D. L. C.; MAGOSSI, A.; DINIZ, A. C.; ANTONIO, L. S. Riscos Ocupacionais em Atividade de Coleta de Resíduos Sólidos. E\&S Engineering and Science, $v$. 3, n. 1, p. 3-17, 2015.

ENRIQUEZ, E. Perda do trabalho, perda da identidade. Relações de trabalho contemporâneas, v. 5, n. 9, p. 53-73, 1999.

GALDINO, S. J.; MALYSZ, S. T. Os riscos ocupacionais dos garis coletores de resíduos sólidos urbanos. Revista Percurso, v. 8, n. 2, p. 187-205, 2016.

HARPAZ, I.; FU, X. The structure of the meaning of work: A relative stability amidst change. Human relations, v. 55, n. 6, p. 639-667, 2002.

KUIJER, P. P. F. M.; SLUITER, J. K.; FRINGS-DRESEN, M. H. W. Health and safety in waste collection: Towards evidence-based worker health surveillance. American journal of industrial medicine, v. 53, n. 10, p. 1040-1064, 2010.

LIMA, M. E. A. A relação entre distúrbio mental e trabalho: evidências epidemiológicas recentes. O trabalho enlouquece, p. 139-160, 2004.

LOPES, F. T.; MACIEL, A. A. D.; CARRIERI, A. P.; DIAS, D. S.; MURTA, I. B. D. O SIGNIFICADO DO TRABALHO PARA OS GARIS: um estudo sobre representações sociais. Revista Perspectivas em Políticas Públicas, v. 5, n. 10, p. 41-69, 2012. 


\section{O SENTIDO DO TRABALHO DOS GARIS COLETORES DE RESÍDUOS DOMICILIARES}

MORIN, E. M. Os sentidos do trabalho. Revista de administração de empresas, v. 41, n. 3, p. 08-19, 2001

MORIN, E.; TONELLI, M. J.; PLIOPAS, A. L. V. O trabalho e seus sentidos. Psicologia \& sociedade, v. 19, n. 1, p. 47-56, 2007.

MOW, International Research Team. The meaning of working. New York: Academic Press, 1987.

OLIVEIRA, S. R.; PICCININI V. C.; FONTOURA, D. S.; SCHWEIG, C. Buscando o Sentido do Trabalho. EnANPAD XXVIII Encontro da Anais... ANPAD - Associação Nacional de PósGraduação e Pesquisa em Administração. Curitiba, Paraná, 2004.

ORGANISTA, J. H. C. O debate sobre a centralidade do trabalho. Expressão Popular, 2006.

PINTO, M.S. A coleta e disposição do lixo no Brasil. Rio de Janeiro: Fundação Getúlio Vargas, 1979.

PRATT, M. G.; ASHFORTH, B. E. Fostering meaningfulness in working and at work. Positive organizational scholarship: Foundations of a new discipline, p. 309-327, 2003

ROSSO, B. D.; DEKAS, K. H.; WRZESNIEWSKI, A. On the meaning of work: A theoretical integration and review. Research in organizational behavior, v. 30, p. 91-127, 2010.

SANTOS, T. L. F. Coletores de lixo: a ambiguidade do trabalho na rua. São Paulo:

Fundacentro, 1999.

SANTOS, M. C. O.; LIMA, F. D. P. A.; MURTA, E. P.; MOTTA, G. M. V. Desregulamentação do trabalho e desregulação da atividade: o caso da terceirização da limpeza urbana e o trabalho dos garis. Production, v. 19, n. 1, p. 202-213, 2009.

SANTOS, G. O.; SILVA, L. F. F. Os significados do lixo para garis e catadores de Fortaleza (CE, Brasil). Ciência \& Saúde Coletiva, v. 16, n. 8, 2011.

TOLFO, S. R.; COUTINHO, M. C.; BAASCH, D.; CUGNIER, J. S. Sentidos y significados del trabajo: un análisis con base en diferentes perspectivas teóricas y epistemológicas en Psicología. Universitas Psychologica, v. 10, n. 1, p. 175, 2011.

TOLFO, S. R.; PICCININI, V. Sentidos e significados do trabalho: explorando conceitos, variáveis e estudos empíricos brasileiros. Psicologia \& Sociedade, v. 19, Edição Especial 1, p. 38-46, 2007.

VELLOSO, M. P.; SANTOS, E. M.; ANJOS, L. A. Processo de trabalho e acidentes de trabalho em coletores de lixo domiciliar na cidade do Rio de Janeiro, Brasil. Cad. Saúde Públ, v. 13, n. 4, p. 693-700, 1997. 
O SENTIDO DO TRABALHO DOS GARIS COLETORES DE RESÍDUOS DOMICILIARES

WRZESNIEWSKI, A.; DUTTON, J. E.; DEBEBE, G. Interpersonal sensemaking and the meaning of work. Research in organizational behavior, v. 25, p. 93-135, 2003. 